one of the filaments of the Stream into the area, where they were collected. This is consistent with the present idea that this area is one in which water masses and plankton of aretic and tropical origin are mixed ${ }^{1,2,5}$. According to the calculations of Thorson ${ }^{10}$, ophioplutei should be able to survive a journey of this distance.

It is hoped that, as more information is accumulated from the newer Plankton Recorder routes from Scotland to southern Greenland and from Eire to Newfoundland, a better understanding of the dispersal of Ophiopluteus ramosus will be possible.

These studies are aided by contract N6 2558-2834 between the Office of Naval Research, Department of the U.S. Navy, and the Scottish Marine Biological Association. I am indebted to Dr. F. Jensenius Madsen of the Universitetets Zoologiske Museum in Copenhagen for allowing me to examine the slides of North Atlantic echinoderm larvæ that were prepared by Dr. T. Mortensen.

Oceanographic Laboratory,

Craighall Road, Edinburgh, 6.

${ }^{1}$ Bainbridge, V., Nature, 191, 1216 (1961)

${ }^{2}$ Bainbridge, V., and Jones, L. T., ICNAF, Serial No. 966 (1962).

${ }^{3}$ Mortensen, T., Ergebn. Atlant. Plankton Exp., 2, J, 1 (Keil, 1898).

${ }^{4}$ Mortensen, T., Nord. Plankt., 9, 1 (Kiel, 1901).

${ }^{5}$ Semenova, T. N., Sov. rhybo. issled. severo-zapad. Atlant. Okeana, 1962, 201 (VNIRO-PINRO, Moscow, 1962).

' Rae, K. M., Hull Bull. Mar. Ecol., 3, 135 (1954).

7 Thorson, G., Biol. Rev., 25, 1 (1950).

${ }^{8}$ Hansen, P. M. (personal communication).

${ }^{9}$ Hyman, L. H.. 4, 763 (MeGraw-Hill, New York, 1955).

10 Thorson, G., Amer. Assoc. Adv. Sci., Pub. 67, 455 (1961).

\section{Handedness and Facial Asymmetry : Lateral Position of the Nose in Two Racial Groups}

AN association has been found to exist between handed. ness and the lateral position of the 'nose' (as indicated by the subnasale) in 1,033 subjects.

While carrying out another investigation, the opportunity was taken to investigate several factors to determine whether they play a part in the development of 'normal' lateral facial asymmetry. The aim was to contribute to the understanding of the mechanisms of facial growth which are of fundamental importance in both the theory and practice of orthodontics. Results were obtained from two racial groups, one comprising 257 Poly. nesians examined on the Island of Rarotonga, South Pacific, and the other 772 Australians of European stock examined in Melbourne. In both groups the subjects were consecutive patients presenting for examination except those excluded because they had an upper central incisor missing or had suffered a fracture of a facial bone. The majority of the subjects, 237 Polynesians and 567 Aus. tralians, were 20 years of age or less.

Methods of assessing lateral facial asymmetry have been discussed ${ }^{1}$ and a detailed description given of the method used in this investigation. Briefly, this was that the lateral position of the 'nose' was judged by assessing the relationship of the subnasale to the most lateral parts of the facethe skin areas over the zygions. Seven asymmetry categories were used and given arbitrary values as follows: A 'nose' that was considerably to the left, 3 ; to the left, 2 ; slightly to the left, 1 ; centre, 0 ; slightly to the right, -1 ; right, -2 ; considerably to the right, -3 . Such observations are open to criticism owing to their subjective nature, but tests of reproducibility were satisfactory. Two readings were taken, several months apart, of each of 182 Australians and 101 Polynesians. In the majority of subjects both results were the same and, in both racial groups, the mean of the discrepancies between each pair of results was not significant ${ }^{1}$.

After having recorded the lateral position of the 'nose' of a subject their handedness was.determined by observing' the hand used to write, to throw, to reach and to grip sporting equipment. A subject who was predominantly

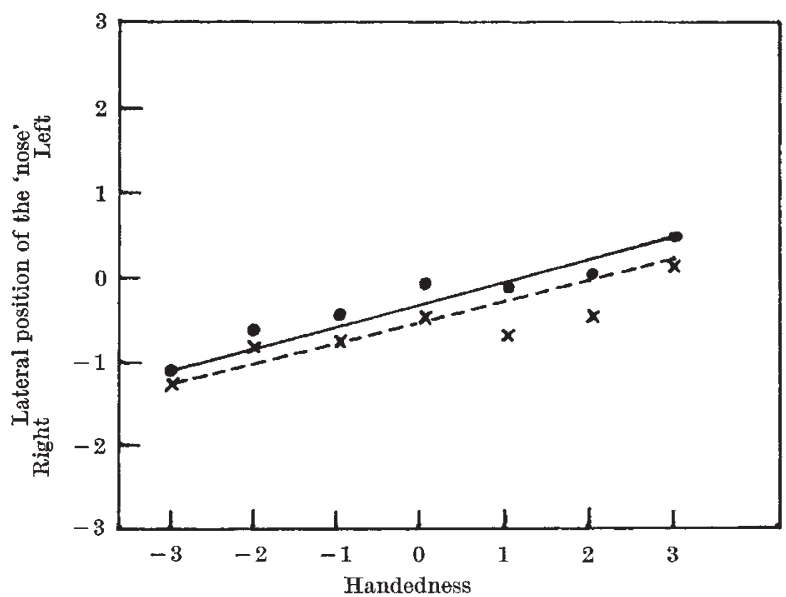

Fig. 1. Association between handedness and the means of arbitrary values denoting the lateral positions of the 'nose' in 772 Australians and 257 Polynesians. (The Polynesian handedness categories: ambidextrous, left-strongly-right and left-slightly-right contained, respectively, only 2,3 and 2 subjects.) Handedness. -3 , right; -2 , rightright; 2 , left-slightly-right; 3 , left. O, Australians; $x$, Polynesians

right-handed, but preferred to use the left hand for one action, was considered to be slightly left-handed; if the left hand was preferred for two actions the subject was classified as right-strongly-left-handed and as ambidextrous if it appeared that both hands were used with approximately equal facility. Slight and strong righthanded tendencies in predominantly Jeft-handed subjects were determined in a similar way. The seven categories used were given arbitrary values from 3 (left-handed) to -3 (right-handed). In only five of the 283 subjects who were tested on two occasions were the handedness assessments different and in each of these there was a change of only one category. The number of subjects in each category was, respectively, from right-hand to lefthand: Australians, 494, 143, 43, 23, 22, 22, 25; Poly. nesians, 208, 20, 5, 2, 3, 2, 17.

Fig. 1 shows, in each handedness category, the mean values for the lateral position of the 'nose' of each racial group, and the regression lines. The points which denote the mean values of those subjects who were ambidextrous, left-strongly-right-handed and left-slightly-right-handed have small negative values. This suggests that there was a slight bias to the right due to unknown factors or to misjudgment on the part of the observer (whose left eye is the dominant one). The regression equations-Australians $Y=-0.34+0.28 X(r=0.37)$, Polynesians $Y=-0.56$ $+0.25 X(r=0.35)$-wore not significantly different and when combined $Y=-0.38+0 \cdot 28 X$. Each was significant, $P<0.001$. Therefore, though of small degree, there is a significant association between the lateral position of the 'nose' and handedness in these subjects.

I thank Sir Arthur Amies and Prof. L. J. Ray for their advice, Dr. G. Gregory for statistical advice and the University of Melbourne Research Fund.

Dental Sehool, PhruIP R. N. SUtton

University of Melbourne.

${ }^{1}$ Sutton, P. R. N. (to be published).

\section{MICROBIOLOGY}

\section{Fermentation of Lactose by Cell-free Extracts of Bacillus anthracis}

THE inability of certain bacterial species and genera to ferment various sugars has important taxonomic value. Such strains, it is stated, do not ferment a particular sugar, and bacteriologists assume that this inability reflects a failure of the organisms to synthesize the proper enzymes. 